\title{
Insilico Design, Synthesis of Hybrid Taurine Amino Acid and Peptide Analogues for Studies on Antioxidant and Hepatoprotective Activity
}

\author{
Sushil Burle ${ }^{1}$, S. Samanta ${ }^{1}$ \\ 1Department of Pharmaceutical Sciences and Technology, Birla Institute of Technology, Mesra, Ranchi, Jharkand-835215, INDIA.
}

\begin{abstract}
Introduction: The liver performs normal metabolic homeostasis of the body as well as biotransformation, extraction and detoxification of many compounds. Due to this it is more susceptible to disease. Near about 900 drug are withdraw from the market due to hepaptoxicity. The objective of the work to synthesis the series of hybrid taurine amino acid and peptide analogues in which the various combinations of taurine amino acid, Di-peptide and Tri- peptide were synthesized. Aims: In this study, we mainly focused on the hepatoprotective aspects of hybrid taurine amino acid peptides analogues before the synthesis we carry out the insilico designing of molecules and from the results of this insilico study we carry forward the synthesis of hybrid compound followed by their in vitro and in vivo studies. Results: the binding affinity of the designed compound towards CYP2E1 (3GPH) was selected on the basis docking score The compound SSSB-16 shows the maximum score having the docking score is -24.84 as compared with single taurine and other taurine hybrid compound. The compound SSSB 15 is second in the list of docking score with the docking score is -24.67 . The reference ligand .having the docking score is -11.90 . All the compounds were screened for their in vitro antioxidant activity by employing DPPH, Nitric oxide scavenging method. From the in vitro result of antioxidant activity those compound which had shown maximum activity till use for hepatoprotective activity. The compound SSSB 3 which is the combination of TaurineGlycine-Glycine shows the maximum activity as compared to all other compounds. Conclusion: From result good activity was noted for SSSB3 (Taurine-Gly-Gly) compound. From this it can be concluded that the amino acid hybrid with future being proof to be novel compound as hepatoprotective activity. It may be use as a supplement with the drugs to reduced hepatotoxicity.
\end{abstract}

Key words: Taurine, Peptides, Cyp2e1, Antioxidant, Hepatoprotection.

\section{INTRODUCTION}

Amino acids are attracting increasing attention as therapeutics due to their role as mediators of key biological functions associated with their low toxicity and high specificity. A large number of peptide -based drugs are now being marketed because new synthetic strategies have been developed in recent year. Many amino acid conjugate is known for reducing hepatotoxicity and improving the physicochemical properties of the various drugs. The amino acids are the dietary constituents and nontoxic as compared to the other carrier. The water soluble amino acids have the ability to increase the water solubility of poorly soluble drug. ${ }^{1}$ Due to this property, amino acid helps to improve the bioavailability and the pharmacokinetics of drugs. In this paper we are trying to focus on the insilico design, synthesis and there antioxidant study of some novel taurine and its hybrid amino acid peptide analogues. Taurine has been mostly used as an antioxidant apart from this it is also used in the treatment of various disease conditions like
Submission Date: 25-01-2017; Revision Date: 18-03-2017; Accepted Date: 10-04-2017

DOI: 10.5530/ijper.51.2s.55 Correspondence: Sushil Burle, Department of Pharmaceutical Sciences and Technology, Birla Institute of Technology, Mesra, Ranchi, Jharkand-835215, INDIA Tel.no: 09890567558

E-mail: sushil_burle@rediffmail.com (Sushil Burle)

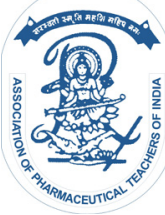

www.ijper.org 
cardiovascular diseases, epilepsy, and macular degeneration, Alzheimer's disease, hepatic disorders, cystic fibrosis and the treatment for alcoholism. ${ }^{2}$

\section{Chemistry of Taurine}

Taurine or 2 aminoethane sulfonic acid Figure 1 is an organic acid. It is also the major constituent of bile acid. It is the derivative of sulfur containing amino acid. The taurine is a small molecule and consist of carbon, hydrogen, nitrogen, sulfur, and oxygen.

Mostly amino acids have L or D - configuration which is having capacity to rotate the plane polarized light. But in case of taurine this property is absent because taurine does not have the $\mathrm{L}$ or $\mathrm{D}$ configurations. Taurine is water soluble and does not easily cross fatty membranes of the body. The physicochemical properties of Taurine [Table 1]., 2,3

In this we manly focus on Insilico drug design it includes Docking, homology modeling, virtual screening, structure activity relationship and scrutiny of data as the essential component. Thus, all components are very important for new drug designing, discovery of new molecules for the target specificity and superior affinity of a compound. Apart from this pharmacokinetic parameter like Absorption, Distribution, Metabolism and Excretion and Toxicity studies are being equally important for the screening of new drug molecules. ${ }^{4}$

In this study we carried out insilico modeling of all the proposed derivatives of taurine hybrid amino acid and peptide analogues using different computational software for the prediction of physico-chemical and physiological parameters. From this the best resulted compound are used to carry out synthesize and furthers for its antioxidant and hepatoprotective study.

\section{MATERIALS AND METHODS}

Docking study was carried out on HP Intel ${ }^{\circledR}$ core 2 duo ( 32-BIT operating system, windows vista using Bisolve IT (Lead IT 2.1.3), 1TB Hard disk. All the structures were drawn by using Chem. Office (version: 3.5) and there energy minimization was done. The Ligprep, were performed by using the Ligand Preparation wizard of Maestro8.5 of Schrodinger software installed o n a Dell system (3.4GHzprocessor, 512RAM, 80GBHard disk with RedHat Linux Enterprise(version3.0) as the operating system. All chemicals which are used for synthesis were purchased from the following companies: SigmaAldrich corpora ration, Merck\& CO., Inc., Rankem, Spectrochem Pvt. Ltd. or Merck India. Solvents were of reagent or HPLC grade and were purified and dried by usingstandard procedure. The melting points of compounds were determined using OPTIMELT (Stanford research systems, California). Reactions were monitored using thin layer chromatography (TLC) on silica gel plates. The spots were visualized either in iodine vapors or under UV light at $254 \mathrm{nM}$ in a suitable UV chamber (Z-Glass, India).Taurine is purchased from the $\mathrm{CDH}$ (Central Drug House) of 99\% assay purity. Elemental analyses were performed. Mass spectra and ${ }^{1} \mathrm{H}$ NMR Spectra were recorded in DMSO.

\section{Receptor and Enzymes}

The co-crystallized structure of the target Protein, of CYP2E1 were obtained from the RSCSB Protein Data Bank (PDB) database; having PDB ID 3GPH (http:// www.pdb.org.).

\section{Ligand preparation}

The proposed Taurine hybrid amino acid and peptide molecules were drawn by using Chem Office 10.0. There energy minimization was performed to recognize low energy conformers and saved in the mol2 file format. These molecules were imported into the project table of the Maestro 5.0, Schrodinger and ligand preparation was done from the application option and exported in the SDF format. Further, these molecules were imported into the docking library of FlexX docking software and used for docking. In this the all molecules were analyzed for their energy of tautomeric and for stereochemistry. ${ }^{5}$

\section{Validation of docking protocol}

In validation of docking the Reference ligand which is bind with receptor protein was removed from the active site of the receptors $3 \mathrm{GPH}$ and re-docked in same receptor and its conformation and orientation were compared with the conformation and orientation of the original X-ray crystallographic structure downloaded from Protein Data Bank. ${ }^{13}$ The RMSD value of was below $2 \mathrm{~A}^{0}$. That indicates that the docking method used has good ability to reproduce conformation. It was used for docking of Taurine hybrid amino acid and peptide.

\section{Molecular docking}

The structures of various conformations of the molecule and targeted receptor protein (3GPH) were loaded into the Biosolve IT Flex X. The Ligand Preparation of all the agonists were done using the application option of maestro 5.0 and loaded as the docking library and then Docking was done to generate best pose by analyzing the interactions and binding affinities and their score, it poses both $2 \mathrm{D}$ and $3 \mathrm{D}$ views generated and saved.,7 


\section{General method for protection of amino acids}

A mixture of purified phthalic anhydride $(0.01 \mathrm{~mol}$,) and amino acid $(0.01 \mathrm{~mol}$,) was heated on sand bath, within 25 minutes the mixture melted; heating was continued for more 10 minutes. The reaction mixture was cooled, the residue was dissolved in ethanol and filtered off water was added to clear filtrate, till turbidity occurs and then the solution was kept at $0^{\circ} \mathrm{C}$ for 24 hours fine crystals of Phthaloyl amino acid separated were filtered and dried and there melting point $\mathrm{Rf}$ value were found out for their characterization. ${ }^{8,9}$

\section{Method for Preparation of Di-Peptides}

\section{Preparation of chlorophosphate ester (CPE) reagent}

Phosphorous pentachloride $(0.06 \mathrm{~mol})$ was taken in a clean and dry $\mathrm{RBF}$, which was cooled at $0-5^{\circ} \mathrm{C}$. To it anhydrous ethanol $(0.06 \mathrm{~mol})$ was added drop wise over a period of $10 \mathrm{~min}$ with constant stirring first $10 \mathrm{ml}$ of anhydrous alcohol was added with due precaution as phosphorous pentachloride gives highly corrosive fumes in presence of air or moisture. After the complete addition of ethanol, mixture was stirred for further half an hour. The CPE reagent thus prepared was stored in tightly closed container.

Caution: Special care was taken while handling phosphorus pentachloride and exposure to eyes and hands was avoided as far as possible.

\section{Phthaloyl Glycine-Gly}

The CPE reagent was added to Phthaloyl Glycine $(0.01 \mathrm{~mol})$ and then stirred to a clear solution. Then Glycine $(0.01 \mathrm{~mol})$ was added to the mixture and stirred to a clear solution. To this mixture triethylamine was added to $\mathrm{pH} 7$ maintaining the reaction temperature below $5^{\circ} \mathrm{C}$. This mixture was left for 6 hours at $0^{\circ} \mathrm{C}$, crystalline product separated was filtered and washed with solvent ether and further deprotection of Phthaloyl group was done, dried and characterized. The procedure was repeated for other combinations of Di-peptides.

\section{Preparation of Tri-Peptides Gly-Gly-Glycine}

The PhthaloylGly-Gly It was then dissolved in CPE using minimum amount. Glycine $(0.01 \mathrm{~mol})$ was added and stirred to clear solution. Triethylamine was added to $\mathrm{pH} 7$ maintaining the temperature below $5^{\circ} \mathrm{C}$. The mixture was left for $6 \mathrm{hrs}$ at $0^{\circ} \mathrm{C}$.The solid separated was filtered, dried and washed with solvent ether. The product obtained is Phthaloyl Gly- Gly-Glycine. It was dissolved in $20 \mathrm{ml}$ ethanol. Hydrazine hydrate (70\%) was added to the mixture and heated on steam bath for 2 hrs. The reaction mixture was cooled, acidified with conc. $\mathrm{HCl}$ and again heated at $50^{\circ} \mathrm{C}$ for $1 \mathrm{hr}$ Phthaloylhydrazide was removed by filtering it out. The filtrate was neutralized with pyridine to liberate free peptide. Removal of solvent was done by vacuum distillation followed by crystallization from ethanol.

\section{ANTIOXIDANT ACTIVITY \\ DPPH Scavenging activity}

DPPH is stable radical that can accept an electron to form a stable diamagnetic molecule due to presences of odd number of electron. This DPPH Methanolic solution shows a strong absorption band at $517 \mathrm{~nm}$ by accepting the electron from the electron donating molecules. It forms colourless 2, 2'-diphenyl-1-picryl hydrazine reduction of the DPPH radicals can be estimated quantitatively by measuring the decreasing in absorbance at $517 \mathrm{~nm}$.

Equal volumes of $100 \mu \mathrm{M}$ DPPH in methanol was added to different concentration of synthesizes compounds from $10-250 \mathrm{uM} / \mathrm{ml}$ in methanol ,mixed well and kept in dark for $20 \mathrm{~min}$. the absorbance at $517 \mathrm{~nm}$ was measured using the spectrophotometer. Plotting the percentage DPPH scavenging against concentration gave the standard curve and the percentage scavenging was calculated from the following equation:

$$
\text { Scavenged }(\%)=\frac{A \text { cont }-A \text { test }}{A \text { cont }} \times 100
$$

Where A cont. is the absorbance of control (control containing all reagents except the test compound), A test is the absorbance of test compound at different concentrations.

$\mathrm{IC}_{50}$ was calculated from a plot between concentration of test compound and $\%$ scavenging. for DPPH ascorbic acid was used as a standard. ${ }^{10}$

\section{Nitric Oxide Scavenging Activity}

The nitric oxide will be generated by sodium nitropruside in presences of an antioxidant scavenger the amount of Nitric oxide generated will be less. The excess nitric oxide will be estimated by Griess reagent. Thenitric oxide will give pink colour complexes estimated at $540 \mathrm{~nm}$.

Procedure: in a reaction mixture containing sodium nitropruside $(4 \mathrm{ml})$.phosphate buffer saline solution (1 ml) and various concentration of synthesized testing compounds were incubated at $25^{\circ} \mathrm{C}$ for about $150 \mathrm{~min}$ 

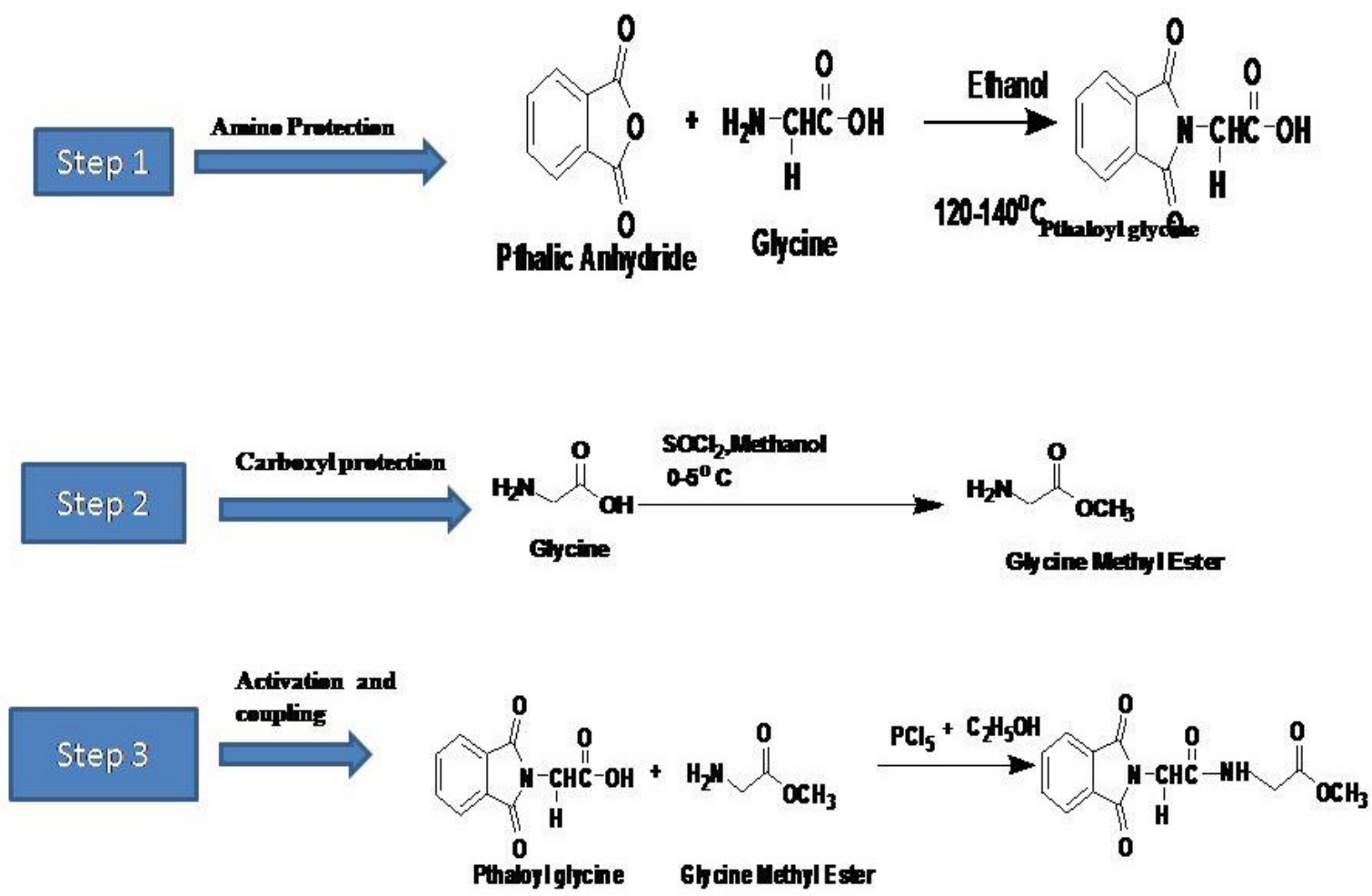

Pthaloyl Glycine Ghcine methol ester

Figure 4:Scheme for synthesis of Taurine -amino acid, Dipeptides, Tripeptides compounds

after incubation, $0.5 \mathrm{ml}$ of reaction mixture containing nitrate was removed and $1.0 \mathrm{ml}$ of sulphanilic acid was added mixed well and allowed to stand for $30 \mathrm{~min}$ in dark at room temperature the absorbance of these solution was measured at $540 \mathrm{~nm}$ against corresponding blank solution without sodium nitropruside. The scavenging and $\mathrm{IC}_{50}$ values were determined. ${ }^{10}$

\section{EVALUATION OF HEPATOPROTECTIVE ACTIVITY}

Those compounds which had shown potent antioxidant activity are further studied for its hepatoprotective activity. The compound includes SSSB1, SSSB2, SSSB3, SSSB6, SSSB7, SSSB9, SSSB15, and SSSB16. The studies were carried out onhealthy Wistar rats weighing from $200 \pm 25 \mathrm{gm}$. The animals were collected randomly from animal house of PBRI, Bhopal. These animals werehoused in separate cages under controlled condition of temperature from 22 to $24^{\circ} \mathrm{C}$. All animal were given standard diet and water ad libitum. This animal also kept at 12: 12 light and dark cycle and finally it is dividing into group eleven containing three animals in each group. The study protocol was approved by the institutional animalethics committee of Pinnacle
Biomedical research institute Bhopal. Registration Approval No:PBRI/IAEC/PN-16046dated 17th Jan 2017.

\section{Acute oral Toxicity test}

Acute oral toxicity test was carried out as per the protocol given in the OECD 423 guidelines for dose levels were selected for acute oral toxicity. $5 \mathrm{mg} / \mathrm{kg}$, $50 \mathrm{mg} / \mathrm{kg}, 300 \mathrm{mg} / \mathrm{kg}$ and $2000 \mathrm{mg} / \mathrm{kg}$ were used as dose range.

\section{EXPERIMENTATION}

All animals were divided randomly into eleven groups with three animals in each group. Group I(T1), receive normal saline p.o. only and served as control, Group II, III, IV, V and VI,VII,VIII.IX,X were treated with carbon tetrachloride $\left(\mathrm{CCl}_{4}\right)$. Group $\mathrm{II}(\mathrm{T} 2)$ received Carbon tetrachloride p. o., Group III(T3) received Silymarin100 mg/kg per day p.o, Group IV(T4) received SSSB-6(60 mg/kg/day), Group V(T5) received SSSB-7 (60 mg/kg/day), Group VI(T6)received SSSB-3 (60 $\mathrm{mg} / \mathrm{kg} /$ day), Group VII(T7) received SSSB-15 (60 mg/kg/day), Group VIII(T8) received SSSB-2 (60 $\mathrm{mg} / \mathrm{kg} /$ day), Group IX(T9) received SSSB-1 (60 mg/kg/day), Group X(T10) received SSSB-16 
(60 $\mathrm{mg} / \mathrm{kg} /$ day), Group XI(T11) received SSSB-9 $(60 \mathrm{mg} / \mathrm{kg} /$ day). All dosing of test samples was done p.o. for 7 days.

Assessment of Hepatotoxicity: After overnight fasting (deprived of food for $16 \mathrm{~h}$ had been allowed free access to water), On the $1^{\text {st }}$ day hepatotoxicity was induced in rats by CCl4 suspension in olive oil $(1: 1 \mathrm{v} / \mathrm{v})$ at a dose of $1 \mathrm{ml} / \mathrm{kg}$ body weight orally by oral gavage tube.

On day 7 , blood was collected by cardiac puncture under mild ether anesthesia. Serum was separated and analyzed for SGOT, SGPT, ALP, Total Bilirubin and Cholesterol using commercial kit of Aspen Lab, Span diagnostic LTD, and Merck India diagnostic respectively. Analysis was done using Rapid Bioautoanlayser (Star 21).

\section{HISTOPATHOLOGICAL STUDIES}

The animals were sacrificed and the abdomen was cut open to remove the liver. Then $5 \mathrm{~mm}$ thick piece of the liver were fixed in Bouin's solution (mixture of $75 \mathrm{ml}$ of saturated picric acid, $25 \mathrm{ml}$ of $40 \%$ formaldehyde and $5 \mathrm{ml}$ of glacial aceticacid) for $12 \mathrm{~h}$ and then embedded in paraffin, using conventional methods andcut into $5 \mathrm{~m}$ microscope for histopathological changes in liver architecture, andtheir photomicrographs were taken. ${ }^{11,12}$

\section{Statistical Analysis}

The mean values \pm SEM was calculated for each parameter. Percentage reduction against the hepatotoxins by the test sample was calculated byconsidering enzyme level difference between the hepatotoxin treated. Fordetermining the significant inter-group difference, each parameter wasanalyzed separately, and one way analysis of variance (ANOVA) was carriedout. Then the individual comparison of the group means values were done usingDennett's' $\mathrm{t}$ ' test procedure [29]. $\mathrm{P}$ values $<0.05$ were considered significant.

\section{RESULT AND DISCUSSION Validation of docking protocol}

In this study, we mainly used flex $\mathrm{X}$ of Biosolve IT. Firstly we validate with the receptor $3 \mathrm{GPH}$ by carrying out the re-docking of reference ligand. In the redocking process ligand which is attached to the co-crystallized structure of protein was removed and re-docked to the active site and RSMD value is noted. The RMSD was below $2 \mathrm{~A}^{0}$ justifying it means the receptor is having well for docking and reproduced good result. [Figure 2] ${ }^{13,14}$

\section{Protein and Ligand preparation}

The co-crystallized structure of the target Protein, of CYP2E1 were obtained from the RSCSB Protein Data Bank (PDB) database; having PDB ID 3GPH (http:// www.pdb.org.) it was prepared by using Flex X. In this modification are done by removing unwanted chains, removing water molecule and set of receptor generation and finally the energy minimization of the protein ligand complex is done. The proposed Taurine hybrid amino acid and peptide molecules were drawn by using Chem. Office 10.0. There energy minimization was performed to recognize low energy conformers and saved in the mol2 file format. These molecules were imported into the project table of the Maestro 5.0, Schrodinger and ligand preparation was done from the application option and exported in the SDF format. Further, these molecules were imported into the docking library of FlexX docking software and used for docking. In this the all molecules were analyzed for their energy of tautomeric and for stereochemistry. ${ }^{18}$

\section{Molecular docking}

All the compounds were docked into the active site of $3 \mathrm{GPH}$ using Flex $\mathrm{X}$ software. The docking scores for taurine hybrid amino acid and peptide analogues as shown in Table 2. By analyzing the scores and hydro-

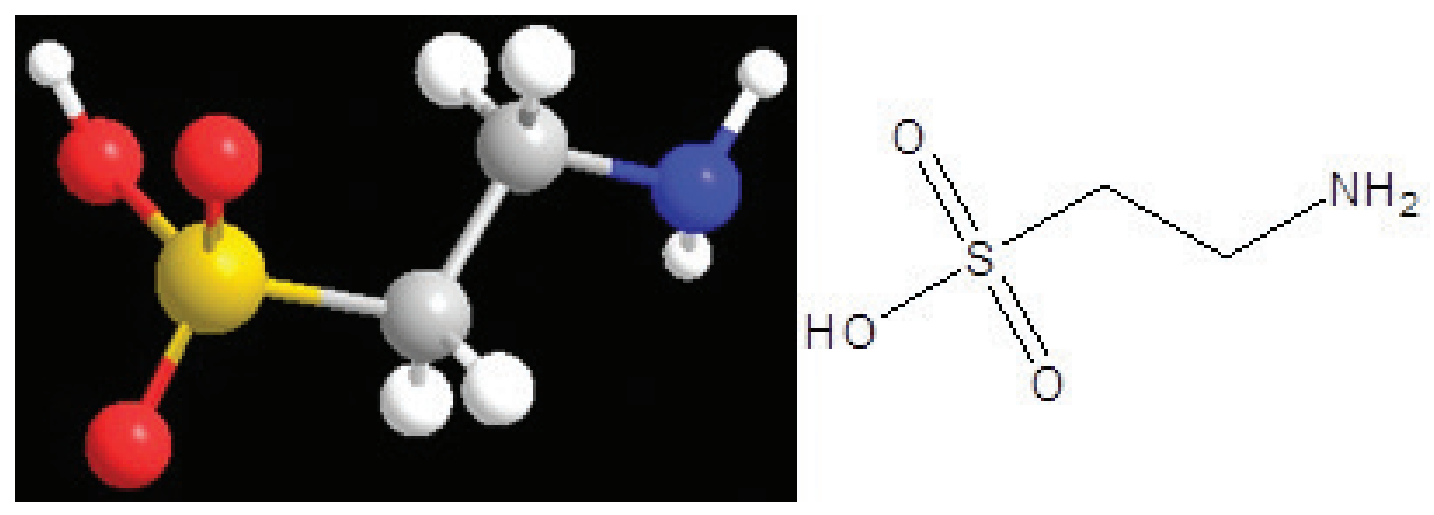

Figure 1: 2D and $3 \mathrm{D}$ structure of Taurine 
philic and hydrophobic interactions, it was found that all hybrid compounds show better binding with the receptor as compared with taurine. This is due to the number of hydrogen bonds and hydrophobic interactions made with the amino acids present at the active site. The compound SSSB-16 shows the maximum score having the docking score is -24.84 as compared with single taurine and other taurine hybrid compound. The compound SSSB 15 is second in the list of docking score with the docking score is -24.67. The compound SSSB16 [Figure 3] shows three hydrogen bonding with amino acid viz. Phe-203, Thr303and Asn 206 and hydrophobic interaction with amino acid viz. Phe 203,

\begin{tabular}{cc} 
Table 1: Physicochemical properties of Taurine \\
\hline Molecular formula & $\mathrm{C}_{2} \mathrm{H}_{7} \mathrm{NO}_{3} \mathrm{~S}$ \\
Molecular weight & 125.15 \\
Physical state & Rod shaped like a crystal \\
Colour & White crystal \\
Odour & Odorless \\
Solubility & Soluble in water \\
Melting point & $300^{\circ} \mathrm{C}$ \\
Optical rotation & $\mathrm{Nil}$ \\
\hline
\end{tabular}
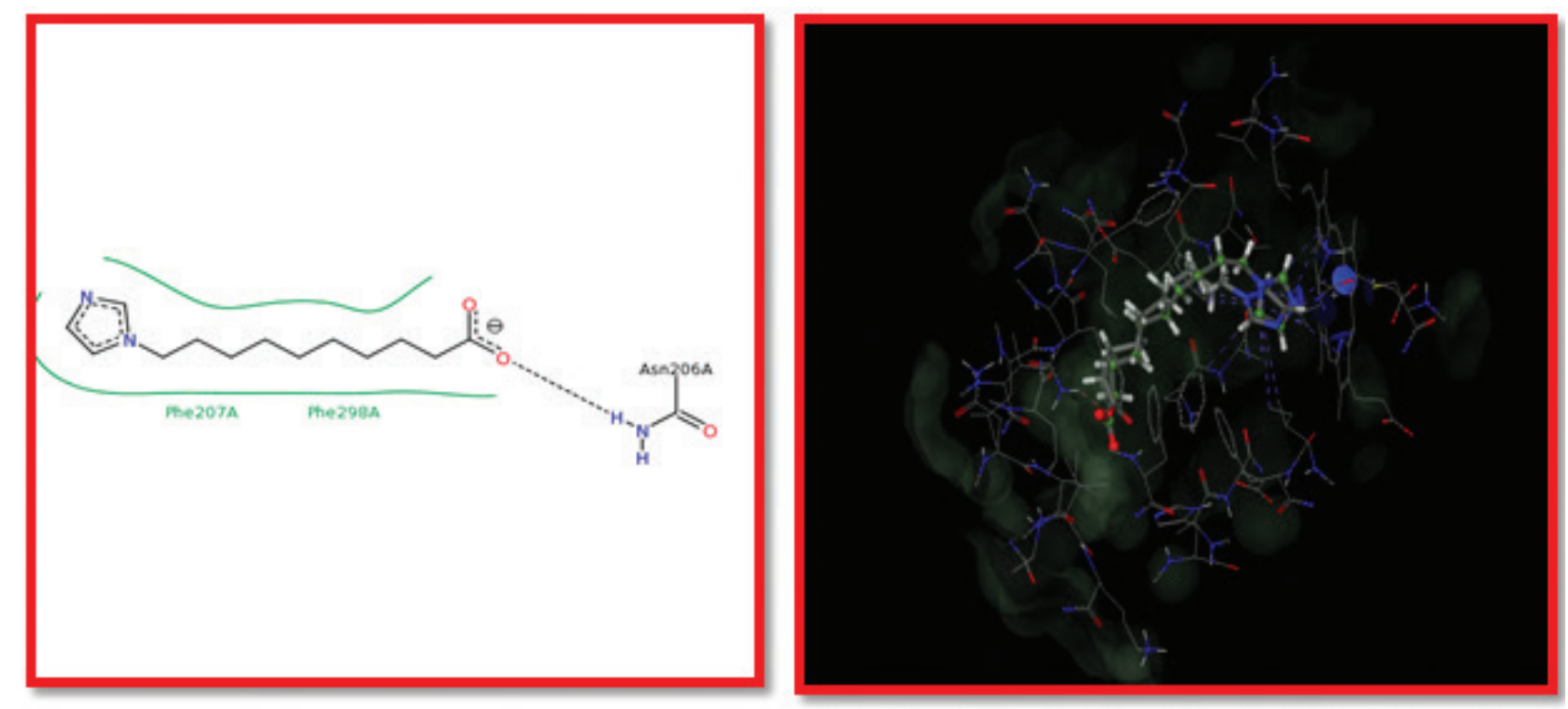

Figure 2: Re-docked poses of the Reference ligands in 3GPH
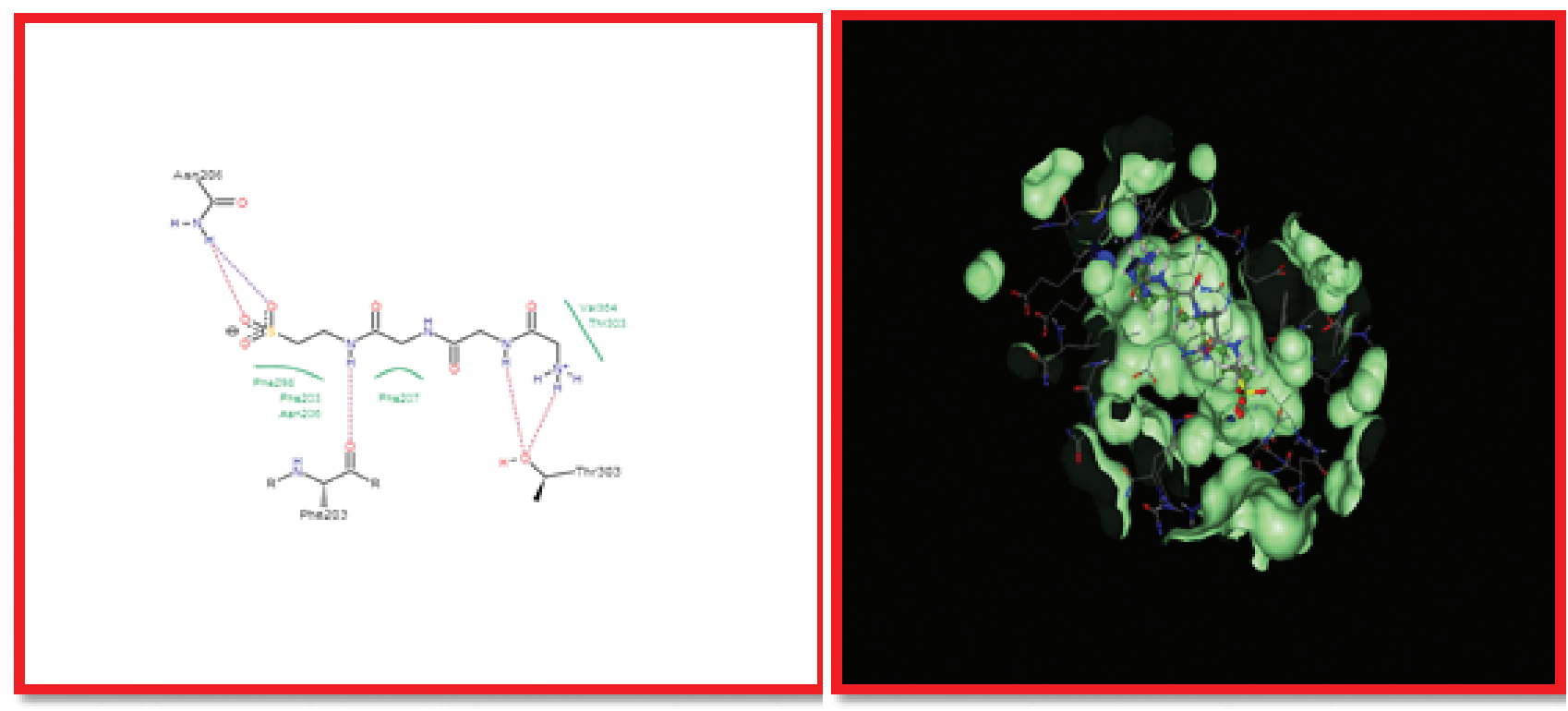

Figure 3: Interaction of SSSB16 with 3GPH 2 Dand 3 D view. 
Asn206, Phe 207, Val 364 and Thr 303 as compared to the reference ligand which is having the hydrogen bonding with the Asn-206 and hydrophobic interaction with Phe-207, Phe-283.having the docking score is -11.90 . From this result it concluded that all the designed hybrid molecules are having activity at $3 \mathrm{GPH}$ receptors. They are making sufficient number of hydrogen bonds and hydrophobic interaction with the active site.

\section{General scheme of preparation hybrid Taurine- Amino acid compounds}

Phthaloyl protecting amino acid $(0.01 \mathrm{~mol})$ was taken in $\mathrm{RBF}$ in ice bath, to this 1:1 ratio of dioxan and water followed by $4 \mathrm{ml}$ of aq. $\mathrm{NaOH}$ till it get dissolves. Add $\mathrm{SOCl}_{2}$ to the solution drop wise allowed to stir for 30 min then remove the ice bath and continue string at room temperature for 4 hrs and monitored by TLC. Then taurine $(0.01 \mathrm{~mol})$ dissolved in water and add to the reaction mixture and stir it continually till reaction proceeds monitored by TLC. Reflux the mixture for 10 min. Solvent is removed by distillation and compound was collected.DeprotectPhthaloyl group and crystalline compound was collected and characterization was done by melting point, Rf value, IR, NMR, and Mass spectra analysis. ${ }^{8,9}$ The same procedure is followed for the preparation of Taurine-single amino acid,Taurine Dipeptides, Taurine-Tripeptides compound preparation. [Figure 4]

- $\quad$ SSSB2 (Taurine-Glycine): Yield: 80\%,Colour: white, Rf value (butanol: acetic acid: water =4:1:1): 0.72, Melting Point: -196-198 ${ }^{\circ} \mathrm{C},{ }^{1} \mathrm{H}$ NMR: $\delta 1.57$ (s, 2H, NH2), $2.12\left(\mathrm{~s}, 1 \mathrm{H}, \mathrm{OH}-\mathrm{SO}_{2}\right), 3.66-3.64\left(\mathrm{t}, 2 \mathrm{H}, \mathrm{CH} 2-\mathrm{SO}_{2}\right)$, 3.74-3.72 (t, 2H, CH2-NH), 3.79(s, 2H, CH2-NH $)$, 8.09 (s, 1H, NH). ESI-MS (m/z): 182.Calculated C: $26.37, \mathrm{H}: 5.53, \mathrm{~N}: 15.38, \mathrm{~S}: 17.60$ observed C: 27.34, H: 5.75, N: 16.32, S: 17.94.

- SSSB5 (Taurine-Alanine):Colour: white solid, Yield: $62 \%, \operatorname{Rf}$ value: (butanol: acetic acid: water $=4: 1: 1) 0.75$, Melting Point: -198-200 ${ }^{0} \mathrm{C}^{1} \mathrm{H}$ NMR: $\delta 1.29(\mathrm{~d}, 3 \mathrm{H}$, CH3), 2.12 (s, 1H, OH-SO $)_{2}, 3.65-3.63$ (t, 2H, $\left.\mathrm{CH} 2-\mathrm{SO}_{2}\right), 3.69-3.66\left(\mathrm{q}, 1 \mathrm{H}, \mathrm{CH}-\mathrm{NH}_{2}\right) \quad 3.72-3.70$ (t, 2H, CH2- $\mathrm{NH}_{2}$ ), 5.21(s, 2H, NH2), 8.09 (s, 1H, NH). ESI-MS (m/z): calculated :196.22 observed mass 197.30, Calculated C: 30.60, H: 6.16, N: 14.28, S: 16.34 observed C: $30.45, \mathrm{H}: 6.82, \mathrm{~N}$ : 14.59, S: 16.16

- SSSB11(Taurine-Valine):Colour: Cream white, Yield: $72 \%, \mathrm{Rf}$ value: : (butanol: acetic acid: water $=4: 1: 1)$ : 0.68,Melting Point:222-230 ${ }^{\circ} \mathrm{C},{ }_{1}^{1} \mathrm{H}$ NMR: : 0.9 (d, $6 \mathrm{H} \mathrm{CH3}), 2.1(\mathrm{~m}, 1 \mathrm{H}, \mathrm{CH}), 2.7\left(\mathrm{t}, 1 \mathrm{H}, \mathrm{CH}-\mathrm{NH}_{2}\right)$, 3.00(d, 2H, CH2-NH), 3.15(t, 2H, NH2), 3.7(t, 2H, $\left.\mathrm{CH} 2-\mathrm{SO}_{2}\right), \quad 8.4(\mathrm{~s}, \quad 3 \mathrm{H}, \quad \mathrm{NH})$. ESI-MS (m/z):
Calculated: 224.28 observed mass 225.30, Calculated C: $37.49, \mathrm{H}: 7.19, \mathrm{~N}: 12.49, \mathrm{~S}: 14.30$ observed C: $38.40, \mathrm{H}: 7.28, \mathrm{~N}: 12.50, \mathrm{~S}: 14.45$.

- SSSB12 (Taurine-Leucine):Colour: white solid, Yield: $71 \%, \mathrm{Rf}$ value : (butanol: acetic acid: water $=4: 1: 1$ ): 0.65,Melting Point:248-250 ${ }^{\circ} \mathrm{C},{ }_{1}^{1} \mathrm{H}$ NMR: $\delta \quad 0.91$ (d, 6H, CH3), 1.35-1.33 (t,2H, CH $\mathbf{H}_{2}, 1.82-1.80$ $\left(\mathrm{m}, 1 \mathrm{H}, \mathrm{CH}-\left(\mathrm{CH}_{3}\right)_{2}\right), 2.12\left(\mathrm{~s}, 1 \mathrm{H}, \mathrm{OH}-\mathrm{SO}_{2}\right), 3.37-$ 3.34(t, 1H, CH-NH ${ }_{2}$ 3.69-3.67 (t, 2H, CH2-SO $)$, 3.79-3.77 (t, 2H, CH2-NH), 5.11(s, 2H, NH2), 8.12 (s, 1H, NH). ESI-MS (m/z): Calculated: 238.30 observed mass 239.40, Calculated C: 40.32, H: 7.61, N: 11.76, S: 13.46 observed C: 40.44, H: 7.82, $\mathrm{N}: 11.59, \mathrm{~S}: 13.16$.

- SSSB 13 (Taurine-Glutamic acid): Colour: white solid, Yield: $79 \%$, Rf value: (butanol: acetic acid: water $=4: 1: 1$ ): 0.7,Melting Point:200-201 ${ }^{\circ} \mathrm{C}^{1} \mathrm{H}$ NMR: $\delta$ 2.06-2.03 (q, 2H, CH2), 2.15(s, 1H, OH-SO $), 2.34-2.32(\mathrm{t}, 2 \mathrm{H}$, CH2-CO), 3.37-3.34(t, 1H, CH-NH ${ }_{2}$ 3.69-3.67 (t, 2H, CH2-SO $\left.{ }_{2}\right), 3.79-3.77$ (t, 2H, CH2-NH), 5.11(s, 2H, NH2), 8.12 (s, 1H, NH), 11.57(s,1H, OH-CO). ESI-MS (m/z): Calculated: 254.26 observed mass 255.30, Calculated C: 33.07, H: $5.55, \mathrm{~N}$ : 11.02, S: 12.61 observed C: $33.77, \mathrm{H}: 5.10, \mathrm{~N}: 11.59$, S: 11.80 .

- SSSB3(Taurine- Gly -Gly):Colour:white solid ,Yield:64\%, Rf Value: (butanol: acetic acid: water $=4: 1: 1$ ) 0.61, Melting Point: $-239.25^{\circ} \mathrm{C},{ }^{1} \mathrm{H}$ NMR: $\delta 1.57$ (s, 2H, NH2), 2.12 (s, 1H, OH-SO 2 ), 3.65-3.63 (t, 2H, CH2-SO ${ }_{2}$ ), 3.72-3.70 (t, 2H, CH2-NH), 3.79 (s, 2H, $\left.\mathrm{CH}_{2}-\mathrm{NH}_{2}\right), 4.14$ (s, 2H, CH2), 8.09 (s, 2H, NH). ESI-MS (m/z): 239. Observed 240.71, Calculated C: $31.06, \mathrm{H}:$ 4.62, N: 12.91, S: 11.40 observed C: 31.12, H: 4.75, N: 13.32, S: 11.94.

- SSSB7 (Taurine-Gly- Valine):Colour: white solid, Yield:73\%, Rf Value: : (butanol:acetic acid: water $=4: 1: 1$ ): 0.68, Melting Point: $185-183^{0} \mathrm{C}^{1} \mathrm{HNMR}: \delta 0.91(\mathrm{~d}, 6 \mathrm{H}$, CH3), 2.17 (s, 1H, OH-SO $), 2.26-2.23(\mathrm{~m}, 1 \mathrm{H}$, CH- $\left.\left(\mathrm{CH}_{3}\right)_{2}\right), 3.55-3\left(\mathrm{~d}, 1 \mathrm{H}, \mathbf{C H}-\mathrm{NH}_{2}\right)$ 3.69-3.67 (t, 2H, CH2-SO $)_{2}$, 3.79-3.77 (t, 2H, CH2-NH), 4.09 (s, 2H, CH2- NH), 5.11(s, 2H, NH2), 8.12 (s, 3H, NH). ESI-MS (m/z): Calculated: 281.33 observed mass 282.46, Calculated C: 38.42, H: 6.81, N: 14.94, S: 11.40 observed C: $38.50, \mathrm{H}: 6.88, \mathrm{~N}: 14.59$, S: 11.54 .

- SSSB 10 ( Taurine-Glycine-Alanine):Colour: white solid, Yield : 78, Rf value: (butanol: acetic acid: water=4:1:1): $\quad 0.55$, Melting Point: $180-182^{\circ} \mathrm{C},{ }^{1} \mathrm{H}$ NMR:1.4 (d, 3H CH3), 2.7(t, 1H, CH-NH $)$ ), 3.00 (d, 2H, CH2-NH), 3.15(s, 2H, NH2), 3.6(t, 2H, $\left.\mathrm{CH} 2-\mathrm{SO}_{2}\right), 3.8\left(\mathrm{t}, 2 \mathrm{H}, \mathrm{CH} 2-\mathrm{CH}_{2}-\mathrm{SO}_{2}\right), 8.5(\mathrm{~s}, 2 \mathrm{H}$, $\mathrm{NH}$ ). ESI-MS (m/z): Calculated: 253.28 observed 
mass 254.30, Calculated C: 33.19, H: 5.97, N: 16.59, S: 12.66 observed C: $34.00, \mathrm{H}: 5.82, \mathrm{~N}: 16.59$, S: 12.16 .

- SSSB 15(Taurine-Glycine-L Leucine):Colour: white, Yield: $70 \%$, Rf value: : (butanol: acetic acid: water $=4: 1: 1$ ): 0.59,Melting Point:243-245 ${ }^{\circ} \mathrm{C}^{1} \mathrm{H}$ NMR: $0.9(\mathrm{~d}, 6 \mathrm{H}$ CH3), 1.6(t, 2H, CH2), 1.8(m, 1H, CH), 2.3(s, 1H, $\mathrm{OH}), 2.7\left(\mathrm{t}, 1 \mathrm{H}, \mathrm{CH}-\mathrm{NH}_{2}\right), 3.00(\mathrm{t}, 2 \mathrm{H}, \mathrm{CH} 2-\mathrm{NH})$, $3.15(\mathrm{~s}, 2 \mathrm{H}, \mathrm{NH} 2), 3.7\left(\mathrm{t}, 2 \mathrm{H}, \mathrm{CH} 2-\mathrm{SO}_{2}\right), 3.8(\mathrm{t}, 2 \mathrm{H}$, $\left.\mathrm{CH} 2-\mathrm{CH}_{2}-\mathrm{SO}_{2}\right), 8.5(\mathrm{~s}, 2 \mathrm{H}, \mathrm{NH})$. ESI-MS $(\mathrm{m} / \mathrm{z})$ : Calculated: 295.36 observed mass 296.30, Calculated C: 40.67, H: 7.17, N: 14.23, S: 10.86 observed C: 40.45, H: 7.82, N: 14.59, S: 10.96.

- SSSB 14 (Taurine-Gly-Glutamic acid): Colour: white solid, Yield: 79\%,Rf value: (butanol: acetic acid: water=4:1:1): 0.65 , Melting Point:244-246 ${ }^{\circ} \mathrm{C},{ }^{1} \mathrm{H}$ NMR: $\delta$ 2.06-2.03 (q, 2H, CH2), 2.15(s, 1H, $\left.\mathrm{OH}-\mathrm{SO}_{2}\right), 2.34-2.32(\mathrm{t}, 2 \mathrm{H}, \mathrm{CH} 2-\mathrm{CO}), 3.38-3.36$ $\left(\mathrm{t}, 1 \mathrm{H}, \mathrm{CH}-\mathrm{NH}_{2}\right)$ 3.69-3.67 (t, 2H, CH2-SO $\left.{ }_{2}\right)$, 3.79-3.77 (t, 2H, CH2-NH), 4.10(s, 2H, CH2-NH), 5.11(s, 2H, NH2), 8.12 (s, 1H, NH), 11.57(s,1H, OH-CO). ESI-MS (m/z): Calculated: 311.08 observed mass 312.12, Calculated C: 34.72, H: 5.50, N: 13.50, S: 10.30 observed C: 34.45, H: 5.09, $\mathrm{N}: 13.59, \mathrm{~S}: 10.16$.

- SSSB16(Taurine-Gly-Gly-Glycine):Colour: white, Yield: 76\%, Rf value: : (butanol: acetic acid: water $=4: 1: 1): 0.68$, Melting Point: $240-242^{\circ} \mathrm{C}{ }^{1} \mathrm{H}$ NMR: $2.7(\mathrm{t}, 2 \mathrm{H}$, $\left.\mathrm{CH}-\mathrm{NH}_{2}\right), 3.00(\mathrm{t}, 6 \mathrm{H}, \mathrm{CH} 2-\mathrm{NH}), 3.6(\mathrm{t}, 2 \mathrm{H}, \mathrm{CH} 2-$
$\left.\mathrm{SO}_{2}\right), 4.3(\mathrm{~s}, 2 \mathrm{H}, \mathrm{NH} 2), 8.3(\mathrm{~s}, 3 \mathrm{H}, \mathrm{NH})$. ESI-MS $(\mathrm{m} / \mathrm{z})$ : Calculated: 296.30 observed mass 297.45, Calculated C: 32.43, H:5.44, N:18.91, S: 10.82 observed C: $32.45, \mathrm{H}: 5.82$, N: 18.59, S: 10.16.

- SSSB4 (Taurine-Gly-Gly-Alanine):Colour: white solid, Yield: $73 \%$, Rf value: (butanol: acetic acid: water $=4: 1: 1$ ) 0.59, Melting Point: $-235-238{ }^{0} \mathrm{C}{ }^{1} \mathrm{H}$ NMR : 1.4 (d, 3H CH3), 2.7(t, 1H, CH-NH $), 3.00(\mathrm{~d}, 4 \mathrm{H}$, CH2-NH), 3.15(s, 2H, NH2), 3.6(t, 2H, CH2$\left.\mathrm{SO}_{2}\right), 3.8\left(\mathrm{t}, 2 \mathrm{H}, \mathrm{CH} 2-\mathrm{CH}_{2}-\mathrm{SO}_{2}\right), 8.5(\mathrm{~s}, 3 \mathrm{H}, \mathrm{NH})$. ESI-MS (m/z): calculated 310.33 observed 311.40, Calculated C: 34.83, H: 5.85, N: 18.05, S: 10.33 observed C: 34.45, H: 5.820, N: 18.59, S: 10.16.

- SSSB9 (Taurine-Gly-Gly-Valine): Colour: White solid crystalline, Yield: 74\%, Rf Value: : (butanol: acetic acid: water=4:1:1) : 0.75, Melting Point:210-215 ${ }^{\circ} \mathrm{C}$, ${ }^{1} \mathrm{HNMR}$ : 0.9(d, 6H CH3), 2.1(s, 1H, OH), 2.7 (t, $\left.1 \mathrm{H}, \mathrm{CH}-\mathrm{NH}_{2}\right), 3.00(\mathrm{~d}, 4 \mathrm{H}, \mathrm{CH} 2-\mathrm{NH}), 3.3(\mathrm{~d}, 2 \mathrm{H}$, $\mathrm{NH} 2), 3.6\left(\mathrm{t}, 2 \mathrm{H}, \mathrm{CH} 2-\mathrm{SO}_{2}\right), 3.7\left(\mathrm{t}, 2 \mathrm{H}, \mathrm{CH} 2-\mathrm{CH}_{2}-\right.$ $\left.\mathrm{SO}_{2}\right), 8.4(\mathrm{~s}, 3 \mathrm{H}, \mathrm{NH})$. ESI-MS (m/z): calculated :281.33 observed mass 282.46, Calculated C:39.04, H: 6.55, N: 16.56, S: 9.48 observed C: $39.45, \mathrm{H}$ : $6.82, \mathrm{~N}: 16.65, \mathrm{~S}: 9.16$

- SSSB 8 (Taurine-Gly-Gly-l Leucine):Colour:- White solid crystalline, Yield: 74\%,Rf Value: : (butanol: acetic acid: water=4:1:1): 0.75, Melting Point:190191 ${ }^{\circ} \mathrm{C}^{1} \mathrm{HNMR}$ : 0.9(d, 6H CH3), 1.6(t, 2H, CH2), 1.8 (m, $1 \mathrm{H}, \mathrm{CH}), 2.7\left(\mathrm{t}, 1 \mathrm{H}, \mathrm{CH}-\mathrm{NH}_{2}\right), 3.00(\mathrm{~d}, 4 \mathrm{H}$, $\mathrm{CH} 2-\mathrm{NH}), 3.3(\mathrm{~d}, 2 \mathrm{H}, \mathrm{NH} 2), 3.6\left(\mathrm{t}, 2 \mathrm{H}, \mathrm{CH} 2-\mathrm{SO}_{2}\right)$,

\begin{tabular}{|c|c|c|}
\hline $\begin{array}{l}\text { Compound } \\
\text { Code }\end{array}$ & Compound Combinations & FlexX Score \\
\hline Reference Ligand & - & -11.90 \\
\hline SSSB 1 & Taurine & -8.94 \\
\hline SSSB 2 & Taurine-Glycine & -14.21 \\
\hline SSSB 3 & Taurine-Glycine-Glycine & -17.34 \\
\hline SSSB 4 & Taurine -Glycine-Glycine-Alanine & -23.42 \\
\hline SSSB 5 & Taurine -Alanine & -16.81 \\
\hline SSSB 6 & Taurine- Glycine-Glycine-Glutamic Acid & -19.20 \\
\hline SSSB 7 & Taurine-Glycine-Valnine & 19.25 \\
\hline SSSB 8 & Taurine- Glycine-Glycine-I Leucine & -23.79 \\
\hline SSSB 9 & Taurine- Glycine-Glycine-Valnine & -22.19 \\
\hline SSSB 10 & Taurine- Glycine-Alanine & -20.31 \\
\hline SSSB 11 & Taurine-Valnine & -17.58 \\
\hline SSSB 12 & Taurine-I Leucine & -15.22 \\
\hline SSSB 13 & Taurine-Glutamic Acid & -13.08 \\
\hline SSSB 14 & Taurine-Glycine-Glutamic Acid & -16.10 \\
\hline SSSB 15 & Taurine-Glycine-I Leucine & -23.42 \\
\hline SSSB 16 & Taurine-Glycine-Glycine-Glycine & -24.84 \\
\hline
\end{tabular}




\begin{tabular}{|c|c|c|c|c|}
\hline \multicolumn{3}{|c|}{ DPPH SCAVENGING ACTVITY } & \multicolumn{2}{|c|}{ NITRIC OXIDE SCAVENGING ACTVITY } \\
\hline SN & COMPOUND & $\begin{array}{c}\text { IC50 value } \\
\mu \mathrm{M}\end{array}$ & COMPOUND & $\begin{array}{c}\text { IC50 value } \\
\mu \mathrm{M}\end{array}$ \\
\hline 1 & Std & 13.27 & Std & 7.41 \\
\hline 2 & SSSB1 & 93.01 & SSSB1 & 99.12 \\
\hline 3 & SSSB2 & 64.01 & SSSB2 & 93.24 \\
\hline 4 & SSSB3 & 43.34 & SSSB3 & 65.86 \\
\hline 5 & SSSB4 & 190.96 & SSSB4 & 279.72 \\
\hline 6 & SSSB5 & 447.1 & SSSB5 & 264.57 \\
\hline 7 & SSSB6 & 113.49 & SSSB6 & 122.47 \\
\hline 8 & SSSB7 & 57.34 & SSSB7 & 90.12 \\
\hline 9 & SSSB8 & 237.15 & SSSB8 & 155.89 \\
\hline 10 & SSSB9 & 127.66 & SSSB9 & 128.25 \\
\hline 11 & SSSB10 & 148.95 & SSSB10 & 154.37 \\
\hline 12 & SSSB11 & 146.28 & SSSB11 & 146.27 \\
\hline 13 & SSSB12 & 169.71 & SSSB12 & 143.14 \\
\hline 14 & SSSB13 & 199.54 & SSSB13 & 226.58 \\
\hline 15 & SSSB14 & 257.24 & SSSB14 & 207.49 \\
\hline 16 & SSSB15 & 121.66 & SSSB15 & 122.45 \\
\hline 17 & SSSB16 & 143.82 & SSSB16 & 138.68 \\
\hline
\end{tabular}

$3.8\left(\mathrm{t}, 2 \mathrm{H}, \mathrm{CH} 2-\mathrm{CH}_{2}-\mathrm{SO}_{2}\right), 8.5(\mathrm{~s}, 3 \mathrm{H}, \mathrm{NH})$. ESI-MS $(\mathrm{m} / \mathrm{z})$ : Calculated: 352.41 observed mass 353.40, Calculated C: $40.90, \mathrm{H}: \quad 6.86, \mathrm{~N}: 15.90, \mathrm{~S}: 9.10$ observed C: 40.45, H: 6.82, N: 15.59, S: 10.16.

- SSSB6 (Taurine-Gly-Gly-Glutamic acid): Colour: white, Yield: $75 \%$, Rf value: : (butanol: acetic acid: water $=4: 1: 1$ ): 0.71,Melting Point: $265266^{\circ} \mathrm{C},{ }^{1} \mathrm{H}$ NMR: $\delta \quad 2.15$ (s, $\left.1 \mathrm{H}, \mathrm{OH}-\mathrm{SO}_{2}\right), 2.21-2.20$ (q, $2 \mathrm{H}, \mathrm{CH}_{2}$ ), 2.34-2.32 (t, 2H, CH2-CO), 3.38-3.36(t, 1H, CH-NH $)$ 3.693.67 (t, 2H, CH2-SO $)$, 3.79-3.77 (t, 2H, CH2-NH), 4.08 (s, 4H, CH2), 5.11(s, 2H, NH2), 8.12 (s, 3H, $\mathrm{NH}), 11.57(\mathrm{~s}, 1 \mathrm{H}, \mathrm{OH}-\mathrm{CO})$. ESI-MS (m/z): calculated : 386.36 observed mass 387.40 , Calculated C: 35.87, H:5.47, N: 15.21, S: 8.70 observed C: 35.45, H: 5.82 , N: 15.59 , S: 8.16

\section{ANTIOXIDANT ACTIVITY}

In order to investigate the free radical scavenging ability of all compounds, the methods like DPPH [di(phenyl)(2,4,6-trinitrophenyl)iminoazanium], Nitric Oxide scavenging were used. DPPH method is widely accepted that its reaction with compounds proceeds through two differentmechanisms, including the direct hydrogen atom transfer and the sequential proton loss electron transfer. Thus, the unpaired electron becomes paired in the presence of a free radical scavenging antioxidant or hydrogen donor, decreasing theabsorption.In the
DPPH antioxidant assay method, we are tested 16 compounds from the concentration ranges from scavenging at concentrations as low as 10 and $250 \mu \mathrm{M}$. The results of antioxidant values expressed in the form of $\mathrm{IC}_{50}$ with different antioxidant markers used are shown in Table 3. out of 16 compounds tested the SSSB3 showed most potent $\mathrm{IC}_{50}$ at $43.34 \mu \mathrm{M}$, when compared to that of the standard ascorbic acid at $13.27 \mu \mathrm{M}$. followed by SSSB 3 compoundsSSSB 7( IC $\left._{50} 57.34 \mu \mathrm{M}\right)$, SSSB2$_{\left(I_{50}\right.}$ $64.01 \mu \mathrm{M})$ also shows the potent activity as compared to $\operatorname{SSSB} 1\left(\mathrm{IC}_{50} 93.01 \mu \mathrm{M}\right)$.

Further, from the antioxidant studies carried out using Nitric oxide scavenging assay for the 16 test compounds, SSSB 3, SSSB 7, and SSSB 2 showed $\mathrm{IC}_{50}$ values at $\mathbf{6 5 . 8 6}, \mathbf{9 0 . 1 2}, 93.24 \mu \mathrm{M}$ respectively when compared to that of the standard ascorbic acid at $7.41 \mu \mathrm{M}$. and the SSSB 1 (IC $50,99.12 \mu \mathrm{M})$.

\section{HEPATOPROTECTIVE STUDY}

After the treatment of animal with $\mathrm{CC}_{4}$, the SGOT, SGPT, ALP, Total Proteins, Bilirubin and Cholesterollevels have been significantly increased. This significant increased in level has reduced markedly in the group of animal treated with $\mathrm{T} 3$ andT6 compounds when compared with $\mathrm{CC1}_{4}$-treated rats. Followed by the T5, T7 as compared to this three compound the compound T9 shows less hepatoprotective activity. Table 4 The 


\begin{tabular}{|c|c|c|c|c|c|}
\hline \multicolumn{7}{|c|}{ Table 4: Biochemical analysis of treated groups } \\
\hline Treatment & SGPT (IU/dl) & SGOT (IU/dl) & ALP (IU/dl) & $\begin{array}{c}\text { TOTAL BILIRUBIN } \\
\text { (mg/dI) }\end{array}$ & CHOLESTEROL (mg/dI) \\
\hline T1 & $33.45 \pm 4.89$ & $50.67 \pm 4.23$ & $100.34 \pm 6.49$ & $0.46 \pm 0.067$ & $61.29 \pm 5.92$ \\
\hline T2 & $96.63 \pm 5.488$ & $111.00 \pm 7.708$ & $206.23 \pm 8.398$ & $1.28 \pm 0.066$ & $134.33 \pm 11.835$ \\
\hline T3 & $56.60 \pm 3.242$ & $62.83 \pm 3.252$ & $111.97 \pm 3.808$ & $0.56 \pm 0.045$ & $72.60 \pm 6.188$ \\
\hline T4 & $79.67 \pm 3.853$ & $87.80 \pm 5.840$ & $166.37 \pm 8.351$ & $1.10 \pm 0.059$ & $118.83 \pm 6.834$ \\
\hline T5 & $67.17 \pm 3.855$ & $75.07 \pm 4.574$ & $140.33 \pm 6.841$ & $0.69 \pm 0.035$ & $103.43 \pm 6.459$ \\
\hline T6 & $64.60 \pm 5.856$ & $70.30 \pm 4.729$ & $134.03 \pm 5.352$ & $0.66 \pm 0.053$ & $91.70 \pm 6.551$ \\
\hline T7 & $69.43 \pm 3.803$ & $81.87 \pm 4.905$ & $153.57 \pm 7.856$ & $0.74 \pm 0.059$ & $111.33 \pm 5.326$ \\
\hline T8 & $83.89 \pm 2.87$ & $100.78 \pm 4.09$ & $178.89 \pm 7.98$ & $1.78 \pm 0.078$ & $135.78 \pm 6.98$ \\
\hline T9 & $70.56 \pm 2.90$ & $78.67 \pm 4.12$ & $155.76 \pm 7.90$ & $0.80 \pm 0.061$ & $112.34 \pm 5.36$ \\
\hline T10 & $85.78 \pm 2.98$ & $98.90 \pm 4.12$ & $167.98 \pm 7.98$ & $1.01 \pm 0.076$ & $136.78 \pm 4.60$ \\
\hline T11 & $84.76 \pm 2.18$ & $99.20 \pm 4.18$ & $178.09 \pm 6.89$ & $1.12 \pm 0.07$ & $126.98 \pm 4.98$ \\
\hline
\end{tabular}

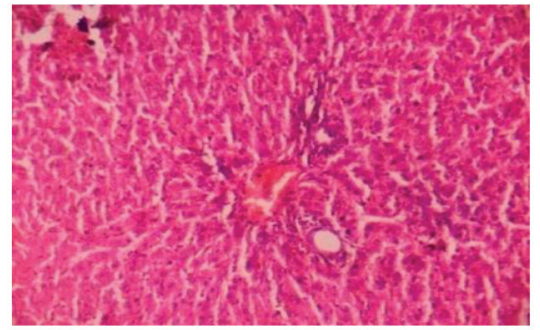

T2

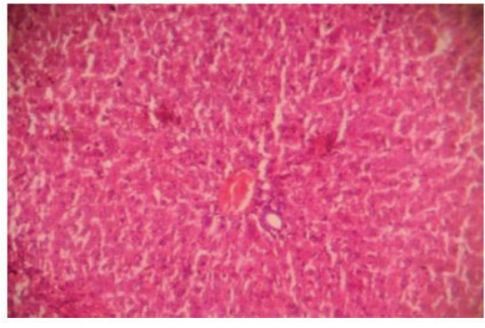

T3

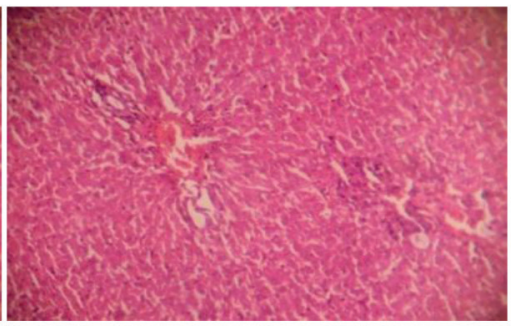

T6

Figure 5: Images of Liver Section at 10X

T2: Photomicrograph of a section from Liver section of $\mathrm{CCl}_{4}$ treated animal,

T3: Photomicrograph of a section from Liver section of Silymarin treated animal,

T6: Photomicrograph of a section from Liver section of compound SSSB3 treated animal

compound T6have shown a better recovery of the hepatocyte which clearly indicated the partial protection of liver cells. Also liver section showed partial disappearance of fatty deposit and necrosis comparable. (Figure 5).

\section{CONCLUSION}

The docking study revealed that hybrid compounds of taurine containing amino acid and peptides hadshows batter binding with all important amino acid residues of $3 \mathrm{GPH}$ receptor .Our study is mainly focused on to established hepatoprotective drug to syntheses of novel hepatoprotective compounds since many drugs causes liver toxicity and due to which they are withdraw from the market in different stages of clinical trial. In this study we found that the hybrid compounds had better docking score as compared to the simple taurine. The compound SSSB16 (Taurine-Gly-Gly-Gly), SSSB15 (taurine-Gly-ILeucine) and SSSB3(Taurine-Gly-Gly) is having docking score $-24.84,-23.42$ and -17.34 while
SSSB 1 (Taurine) is having docking score -11.90. After the satisfactory results of insilico study, we have successfully synthesized a taurine amino acid and peptide analogs, the compounds were purified by recrystallsation using appropriate solvent. The synthetic yields of the generated products ranged from 40 to $60 \%$ and their structures were established by spectraldata. Finally, all of synthesized compoundshave been tested for their antioxidant activities using DPPH method, nitric oxide scavenging method and for hepatoprotective activity. From result good activity was noted for SSSB3 (Taurine-Gly-Gly) compound. From this it can be concluded that the amino acid hybrid with future being proof to be novel compound as hepatoprotective activity. It may be use as a supplement with the drugs to reduced hepatotoxicity.

\section{ACKNOWLEDGMENT}

The authors are grateful to the All India Council of Technical Council, New Delhi, for providing AICTE QIP fellowship assistance for the successful completion 
of this work and also thankful to the Department of Pharmaceutical Sciences and Technology, Birla Institute of Technology, Mesra, for providing lab facilities

\section{CONFLICT OF INTEREST}

The authors declare no conflict of interest

\section{ABBREVIATIONS USED}

CYP2E1:Cytochrome P450 2E1;RMSD: Root-MeanSquare Deviation; CPE: Chlorophosphate Ester;TLC: Thin layer chromatography; DPPH: 2,2-diphenyl1-picrylhydrazyl; $\mathbf{C C l}_{4}$ : Carbon tetrachloride; SGOT: serum glutamic oxaloacetic transaminase; SGPT: serum glutamic-pyruvic transaminase; ALP: Alkaline phosphatase; IR: infrared spectroscopy; NMR: Nuclear magnetic resonance.

\section{REFERENCES}

1. Prakash S, Maji D, Samanta S, Shina RK. Design, synthesis and ant diabetic, cardiomyopathy studies of Cinnamic acid-amino acid hybrid analogs. Med Chem. 2014;4:345-50. https://doi.org/10.4172/2161-0444.1000163.

2. Stephen WS, Junichi A, Mahmood M. Role of antioxidant activity of taurine in diabetes. Can J Physiol. Pharmacol. 2009;87(2):91-9.

3. Huxtable RJ, Bressler R. Effect of taurine on a muscle intracellular membrane. Bio chem. Biophys. Acta. 1973;323(4):573-83. https://doi.org/10.1016/00052736(73)90165-X.

4. Meraj K, Mahto MK, Christina NB, Desai N, Shahbazi S, Bhaskar M. Molecular modeling, docking and ADMET studies towards development of novel Disopyramide analogs for potential inhibition of human voltage gated sodium channel proteins. Bio information. 2012;8(23):1139-46. https://doi. org/10.6026/97320630081139; PMid:23275710 PMCid:PMC3530882.

5. QikProp2.0 User Manual UNIX, Schrödinger, L L C Schrödinger, 2002.

6. Lipinski CA, Lombardo F, Dominy BW, Feeney PJ. Experimental and computational approaches to estimate solubility and permeability in drug discovery and development settings. Advanced Drug Delivery Reviews. 2001;46:3-26. https://doi.org/10.1016/S0169-409X(00)00129-0.

7. Nishant T, Kumar DS, Kumar VVLP. Computational Methods for Protein Structure Prediction and Its Application in Drug Design J. Proteomics Bio inform. 2011;4:289-93.

8. Sinha SK, Praveen B, Shrivastava PK, Shrivastava SK. Synthesis, characterization and biological evaluation of some glutathione inducing amino acid conjugates of valproic acid with reduced hepatotoxicity. Asian Pacific Journal of Tropical Disease. 2012;2:S218-22. https://doi.org/10.1016/ S2222-1808(12)60155-8.

9. Vertesaljai P, Biswas S, Lebedyeva I, Broggi E, Asiri AM, Katritzky AR. Synthesis of Taurine-Containing Peptides, Sulfonopeptides, and $\mathrm{N}$ and O-Conjugates. J Org Chem. 2014;79(6):2688-93.https://doi.org/10.1021/ j0500181g ; PMid:24568296.

10. Tenpe CR, Upaganlawar A, Burle S, Yeole PG. In vitro Antioxidant And Preliminary Hepatoprotective Activity OfOroxylumIndicum Vent Leaf Extracts. Pharmacology online. 2009;1:35-43.

11. Rajasekaran A, Periyasamy M. Synthesis and Evaluation of Hepatoprotective Activity OfSome New Mannich Bases Bearing Benztriazole Moiety. J ChilChem Soc. 2010;55:3. https://doi.org/10.4067/S0717-97072010000300021.

12. M.I. Kazeem, H.A. Bankole, A.A.Fatai. Protective effect of ginger in normal and carbon-tetrachloride induced hepatotoxic rats. Annals of Biological Research, 2011; 2 (1): 1-8.

13. Burle S, Samanta S. In silico design and discovery of some novel hybrid amino acid analoges for their hepaptoptorectve activity. International Journal of Pharmaceutical Research. 2015;7(4):7.

14. FlexX, Protein and Ligand Dockers, User and Technical Reference as part of Lead IT 2;3:11-378.

15. Wadood A, Ahmed N, Shah L, Ahmad A, Hassan H, Shams S. In-silico drug design: An approach which revolutionarised the drug discovery process. OA Drug Design \& Delivery. 2013;1(1):3. https://doi.org/10.13172/2054-4057-11-1119.

\section{PICTORIAL ABSTRACT}

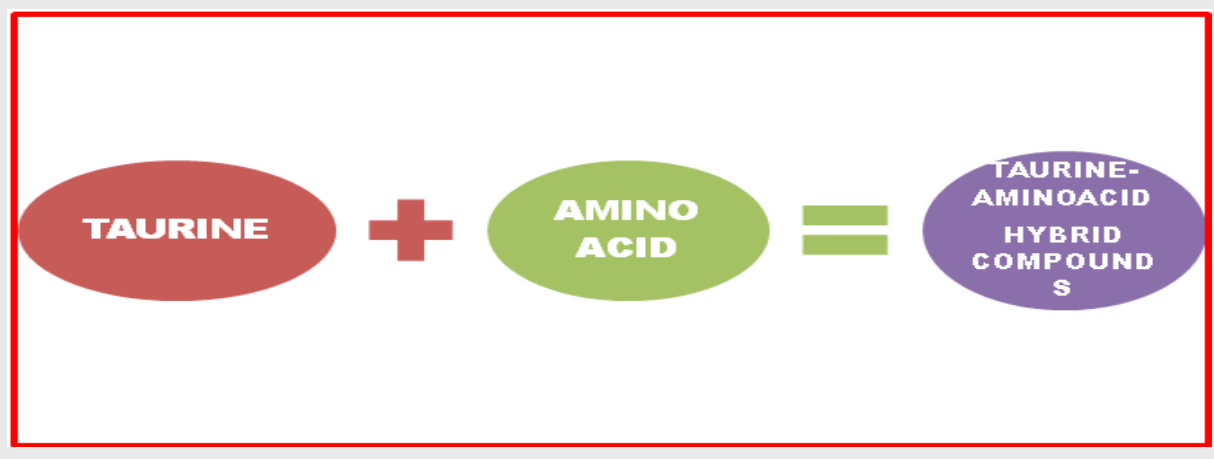

SUMMARY

A novel taurine amino acid hybride analogues having dipeptide and tripeptides have been synthesized and final compounds were charactrised by FTIR, 1HNMR and mass spectroscopy. Compound SSSB 3 significantly reduced the levels of liver enzyme markers like SGOT, SGPT, ALP, bilurubin and cholesterol which was elevated by CCL4 administration. In present study it was found that the compound SSSB3 (Taurine-Gly-Gly) exhibited potent antioxidant and hepaptoportective activity. 


\section{About Authors}

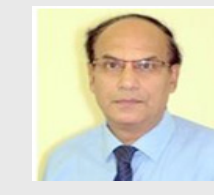

Dr. S Samanta: He is Professor in the Department of Pharmaceutical Sciences and Technology, Birla Institute of Technology, Jharkhand India. He is having 32 years of teaching and research experience and presently guiding $7 \mathrm{PhD}$ students. He is supported by UGC-MRP project for installation of FlexX and Reaction station in Medicinal Chemistry Research Labs. His area of interest includes anti-diabetics, analgesics, anti-inflammatory, and hepatoprotective agents. He has a patent on product and process on peptide based oral anti-diabetic compounds. He has number of International publications and recognition in the field of research and teaching.

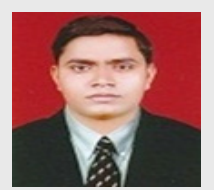

Mr. Sushil Burle: Working as AICTE QIP research fellow in the Department of Pharmaceutical Sciences and Technology, Birla Institute of Technology, Jharkhand India.

Cite this article: Burle S, Samanta S. Insilico Design, Synthesis of Hybrid Taurine Amino Acid and Peptide Analogues for Studies on Antioxidant and Hepatoprotective Actvity. Indian J of Pharmaceutical Education and Research. $2017 ; 51(2 s): 98-109$. 